\title{
National Styles of Enterprise Management in Central European Countries: Conceptualization of Research
}

\author{
Mieczysław Morawski \\ Department of Enterprise Science, Faculty of Economy, Management and Tourism Wrocław University of Economics, \\ 58-500 Jelenia Góraul. Nowowiejska 3 Poland \\ *Corresponding Author: mieczyslaw.morawski@ue.wroc.pl
}

Copyright ( 2014 Horizon Research Publishing. All rights reserved.

\begin{abstract}
The paper presents reasons underlying the choice of research direction and the research project assumptions focused on the conceptual category - national management styles. Additionally, there are presented comments to research assumptions reflecting the Author's standpoint, as well as conclusions based on the conducted preliminary studies. In the Author's opinion the performed analysis will facilitate defining qualities specific for Polish national management style and also NMS in other Central European countries.
\end{abstract}

Keywords National Management Style, Polish National Management Style, Enterprise Management

\section{Introduction}

In the times of a breakthrough we expect from science and scientists to provide responses to many questions and uncertainties. We have to face diversified dilemmas in the areas interpreted by management science. New phenomena occurring in an organization and management require a different perception. Therefore the analysis, valuation and anticipation of events and processes occurring in contemporary economy has to be based on research worker's sensitivity and proper instruments adequate for the new economy based on liberalization, information, globalization, networking, innovation. The need arises to obtain new knowledge about the occurring phenomena, facts and their reasons and to articulate it in both academic and business environment. A settlement may be risked that since the origins of management science such challenges have never occurred in the study of an organization or its management which extensiveness, intensity and novelty would stimulate undertaking basic, cognitive research. Basic research in management science focuses on separating new phenomena, interdependencies and relations in an organizational reality. New theories and approaches are crystallized. New terms become necessary to describe new phenomena and processes, or the existing ones which, however, are explained by these new terms in a different way. According to the Author of the hereby study national management style (NMS) represents one of such new terms. Even though the designations comprising this term are traditional ones when put together they allow to capture two following issues. Firstly, NMS category reflects changes occurring in an enterprise where leading resource is represented by people [The Future of HR Profession 2002], therefore interpersonal factors [Trompenaars, Hampden-Turner 2004] and their impact on effective organizational resources implementation constitute the basic research dimension. Secondly, rapid development of economies in many countries encourages for researching success factors within enterprises located there. Certainly it is high time to go beyond the traditional model of Anglo-Saxon management [Hampden-Turner, Trompenaars 1993]. It is true, though, that this model established the background for civilization success in a global dimension, however, more and more examples of emerging economies require to take into account also other management solutions. These solutions may be effective and recognized as a more universal pattern of an organization functioning since they go beyond the local context. They definitely constitute, if not just an alternative to Anglo-Saxon management model, its important supplement.

The hereby paper is of theoretical and conceptual nature. Preliminary assumptions of a research project are presented with the national management style as the key conceptual category. Survey studies will be carried out in Polish and Ukrainian enterprises.

\section{Reasons underlying the Choice of Research Focus}

Dynamic development of such countries as e.g. China, India, Brazil, Turkey which, so far, have been occupying peripheries of civilization, following Western World values, results in increased interest in the sources of these economies becoming successful. Definitely, the basic questions to be answered refer to specific qualities of local management. This reminds the times of growing interest in Japanese 
management methods, which became attractive when Japanese economy and enterprises representing it started winning competitive advantage over American and European companies. Currently a similarly increasing attention is paid to Korean companies' management, following the spectacular success of Samsung, Kia and other enterprises. The formation of modern management in USA and Europe has many underlying reasons: the opinion of pioneers in management science, systematically appearing new "conceptual products" offered by consultancy companies and influential advisors, systemic concepts and implemented methods facilitating management processes introduced in the leading American, European and Japanese corporations, resulted in the fact that for many years the "Western" approach and, in fact, the Anglo-Saxon one to the theory and practice of management, dominated or even created an undisputable model of solutions [Gesteland 2002]. Undoubtedly the processes of globalization, computerization, networking did support such domination [Hofstede 2010]. Therefore, when the canon of management solutions is different from an Anglo-Saxon one the dysfunctions or imperfections are pointed to. The specific nature of management in different cultural, economic or technical conditions does not have to be regarded as a pathological but, in fact, represents an efficiently formed - in given conditions - synergistic effect manifested by the accepted and generalized system of Chinese or Arabic management [Bjerke 1999], Polish, Czech etc. Countries and nations referred to as emerging economies can also bring in their input to the theory of management science, e.g. regarding the phenomenon of entrepreneurship, approach to human resources management, brand creation, etc.

\section{Research Assumptions}

Research thesis: National management styles (NMS) in enterprises of the studied countries differ significantly from NMS of enterprises influenced by Anglo-Saxon management patterns.

Research problem: What are the differences and similarities: their size, scope, permanence, transformations in time, firstly, between NMS of the studied countries and secondly, jointly Central European countries and countries under the influence of Anglo-Saxon management patterns.

Research questions: What are the qualities of NMS in particular countries, e.g. German work organization, processes for professional competencies training, focus on performance, etc.; Ukrainian fantasy and disregarding limitations, Polish family entrepreneurship, relations in business, Czech pragmatic attitude and ability for flexible cooperation with different partners, etc., can enhance management in other countries, due to e.g. their efficiency?

To what extent does the formed NMS, applied in the majority of enterprises in a given national economy in central Europe, represent the imitation of "Western values" and to what degree the exemplification of local conditions?
What are the crucial determinants resulting from local conditions and having decisive influence on NMS qualities?

Is it possible to define the specific NMS qualities which are common for Central European enterprises?

Which common qualities represent NMS strong points in global economy?

To what extent NMS qualities, in the studied countries, facilitate knowledge-based economy development?

Which of the analyzed NMS can enhance the establishment and development of intellectual capital and its components?

Which of the studied NMS can guarantee high level of competitiveness?

What are the threats for these enterprises resulting from the fixed assumptions underlying NMS in the context of globalization, computerization, competitiveness, etc.?

Does business partnership, in its diversified forms and stages, result in mutual absorption of some NMS qualities by enterprises originating from different Central European countries?

Definition:

NMS represents the concept:

- historically and culturally determined, formed in time, informal,

- significantly influencing attitudes, behaviours and decisions of people involved in management processes,

- as the method for reality perception in an organization and its environment,

- reflected in thinking and acting,

- for constructing, influencing, modifying and development of an enterprise resources,

- functioning by exerting impact, motivating, communication and other interpersonal factors.

NMS components:

- national and organizational culture,

- method for valuation/perception of reality in an organization and outside it,

- attitudes, behaviours and decisions made by people in management processes,

- resources subject to influence,

- interpersonal factors.

\section{Comments on the Research Objectives}

NMS category represents, to an extent, a closed concept by accepting certain elements which define particular research areas. The listed components are supposed to reflect the leading role played by people in an organization. Therefore it is accepted that the level of reality perception, by both owners and managers as well as the remaining members of an organization, has been significantly determined by the history, national culture, personal and collective experience. These determinants are reflected in the approach to resources at the disposition of an organization. 
NMS category represents, at the same time, an open concept since it has to cover diversified local factors typical for social environment. Such environment persists under major impact of primary, causative forces in the form of historical events (political, economic, social), memories of them as well as their evaluation resulting from self-reflection presented by individuals and social groups. National culture is established based on such memories. This results in its universal quality and is disseminated by means of the related set of preferences and obligations understood and accepted by community members. National culture codes are transferred into the grounds of an organization and take the form of a certain organizational culture. An individual element exerts impact on the dimension of culture and manifests itself in the style of a given entrepreneur (owner, manager). This style refers to company management, i.e. in the perspective of accepted NMS category it means determining to what extent motivation, communication and other forms of interpersonal relations influence the approach towards taking advantage of the due resources, which is reflected in adequate attitudes, behaviours and decisions of both supervisors and subordinates [The Future of HR Profession, 2002].

The accepted research perspective means concentrating on interpersonal relations, however, in their direct, dynamic reference towards taking advantage of organization resources in the overall management process. Owing to potential difficulties related to the analysis of such, most frequently, informal relations and interdependencies it seems founded - at least at the initial identification stage - to concentrate on a limited in number group of small and medium enterprises. In small and medium sized companies it is usually easier to capture processes involving people. Firstly, the existence of one dominating entrepreneur (manager) can be assumed, or a small decision-making group, the management style of which is relatively easily imposed on other members of an organization. The attitudes and behaviour of all or the majority of a small or medium enterprise members are therefore characterized by common logic. Additionally, it is much more feasible in a small or medium sized company, than in a large corporation functioning in line with specific procedures and standards, to identify NMS influenced by individual experiences of entrepreneurs.

In the Author's opinion while selecting the adequate sample of enterprises for analysis it is required - apart from limiting them to the group of small and medium sized companies - to search for examples of success in business in Polish conditions. It may not, however, be ruled out that some identified NMS qualities may be enriched by Anglo-Saxon patterns for managing enterprises in highly developed countries. Therefore the research will be carried out from the perspective of contemporary organization development directions recognized as the most important ones. These are as follows:
- competence
- leadership
- team work
- innovation
- information
- entrepreneurship
- cooperation

In the first stage of research, the author wants to focus on identifying the specific characteristics of Polish national style of management. The study area refers to companies belonging to the rapidly growing creative industries in Poland. Currently, the companies of the creative industries is employed in this country more than 300,000 people and the number is growing rapidly. The vast most of these are based on the company's talented young Polish entrepreneurs, who build their business from scratch. These companies are on the verge of rapid expansion in the global markets. Their management style will be confronted with the dominant Western pattern of management.

In creative industries competitive advantage is obtained through the ability to create new values. An organization physical property is less important, however, what it knows and is capable of accomplishing in the knowledge-based economy is of much greater significance. Visible assets do not present the object of special interest in a modern organization, but rather its invisible resources including mainly knowledge based on human capital. In consequence, in companies subject to strong competition, the appropriate approach to managing people gains a special meaning. It is particularly important to gain knowledge from the best valued employees presenting core competences. In creative industries the professional enterprise has to employ the best people. Each other solution is not acceptable in the conditions of the global rivalry based on the knowledge, competences and innovations. Their ideas, knowledge and practical skills guarantee generating the disproportional high value from the resources which are made available for them by the enterprise.

For research purposes developed a pattern of basic characteristics of national style of management for creative industries (Table.1). 
Table 1. The pattern of basic characteristics of national style of management for creative industries

\begin{tabular}{|c|c|c|}
\hline $\begin{array}{c}\text { The elements of } \\
\text { national management } \\
\text { system }\end{array}$ & The content of directives & $\begin{array}{c}\text { The features of the } \\
\text { enterprise }\end{array}$ \\
\hline Strategy & $\begin{array}{l}\text { Strategic management based on vision, mission and simple rules; identification of market } \\
\text { opportunities and occasions; short time strategic planning; parallel actions concerning both } \\
\text { environment analysis and company analysis; parallel actions concerning both programme } \\
\text { implementation and effects monitoring; a customer in the centre of attention }\end{array}$ & \multirow{5}{*}{$\begin{array}{l}\text { flexibility, creativity, } \\
\text { partnership, innovation, } \\
\text { entrepreneurship }\end{array}$} \\
\hline Preferred values & $\begin{array}{l}\text { Open communication; informal contacts; change acceptation; lack of distance; } \\
\text { responsibility; the feeling of partners community in creative actions; professionalism ethos, } \\
\text { trust, dialogue, partnership; lack of distance between employees; expert power; authority is } \\
\text { based on knowledge and personality }\end{array}$ & \\
\hline $\begin{array}{l}\text { Basic management } \\
\text { methods }\end{array}$ & Methods based on intellectual capital & \\
\hline $\begin{array}{l}\text { Organizational } \\
\text { structure }\end{array}$ & $\begin{array}{c}\text { Small hierarchy, teams having changeable tasks and line-up; informal expert nets joined } \\
\text { with interests and professional passion; changeable organizational roles of knowledge } \\
\text { employees; processes and procedures creating value added for a customer }\end{array}$ & \\
\hline Personnel politics & $\begin{array}{l}\text { Recruiting employees with excellent potential and vocational qualifications; orientation to } \\
\text { employees competencies development; rewarding of inventiveness, ability to experiment, } \\
\text { sharing knowledge with others, the increase of personal qualifications; encouraging and also } \\
\text { creating conditions for personal and informal contacts between employees }\end{array}$ & \\
\hline
\end{tabular}

Source: own study.

\section{The Results of the Conducted Preliminary Research}

The Author conducted research in a few small and medium enterprises. The sample is too small to put forward any generalizations, however, certain common elements of the analysed companies are well visible. The presented case of one of the studied enterprises represents a good example of Polish NMS emerging picture (Table. 2).

It is an engineering company specializing in the production of high quality measurement tools for such industry sectors as electrical power, construction and telecommunication. The company represents one of the largest manufacturers of electric meters in Europe. The major part of production focuses on innovative, high-tech electric meters which are not manufactured by any other producers worldwide. The company offer reaches several dozens of countries including currently very promising and important markets as such: Russia, Ukraine and the Far East, e.g. India. New products manufactured by the company represent infrared cameras and electric energy quality meters. The company was established in 1998, since 2008 it has been operating as a joint-stock company listed at the Warsaw Stock Exchange.

The solutions accepted in the company constitute an interesting combination of an extended motivation system combined with social benefits and visible care about employees and also friendly approach to their individual problems, long-term employment, relatively low level of employment level fluctuations, internal recruitment and promotion preference, emphasis on high professional competencies, especially with reference to specialists: electronic designers, technical and commercial consultants, as well as managers and leaders. Mutual friendliness and sympathy can be sensed in the company, support and assistance in current issues are experienced on a daily basis, personnel comes forward with interesting initiatives which extend their professional duties. Many activities are undertaken for the benefit of constructing strong relations between employees and the company. Well recognized management methods and techniques are selected and significantly modified in order to create original and integrated management systems, e.g. focused on production.

The company is respected, long-time employees with employment, remembering the pioneering phase of business development. One of the most valuable employees of the company is production director. He worked with the company for 16 years. He started as a fitter in the production of electronic components. Then he served as an assembly line operator, technician, technologist, manager of technology. His present high position in the company determines knowledge of technology and manufacturing processes, managerial skills and ability to work with people. It is well appreciated by the former managers, who are now his colleagues and subordinates. According to the director of its success decided active and enthusiastic approach to duties, perform additional tasks, continuous improvement of skills.

Subsequent research is supposed to examine the extent to which the presented qualities constitute properties typical only for one analysed company and to what extent they can become a starting point for the identification of Polish NMS attributes. It seems, however, possible to distinguish the specific qualities which can provide an answer to the question: what is Polish effective management characterized by.

\section{Discussion}

The initial research took the form of a survey and was carried out in the course of the recent several months. A few selected enterprises from Poland were covered by the study. The research had the form of a survey interview conducted among the middle and senior level managers. 
Table 2. Selected NMS qualities in the analysed company

\begin{tabular}{|c|c|}
\hline NSZ qualities & Engineering company \\
\hline Company origins & $\begin{array}{l}\text { The company founded by a group of } \\
\text { professionals originating from a previous } \\
\text { company }\end{array}$ \\
\hline Preferred values & $\begin{array}{l}\text { high level of professional competencies } \\
\text { good interpersonal relations } \\
\text { individual approach to employees' problems } \\
\text { open expression of opinions regarding both the } \\
\text { company and team issues } \\
\text { creativity in thinking and functioning } \\
\text { flexibility in performing organizational } \\
\text { functions and roles }\end{array}$ \\
\hline $\begin{array}{l}\text { Basic management } \\
\text { methods }\end{array}$ & $\begin{array}{l}\text { management by competencies } \\
\text { management by projects }\end{array}$ \\
\hline $\begin{array}{l}\text { Management } \\
\text { systems }\end{array}$ & $\begin{array}{c}\text { Integrated production system based on } \\
\text { modified kaizen assumptions, quality } \\
\text { assurance, } 5 \mathrm{~S} \text {, value stream mapping, supply } \\
\text { chain management, purchasing process } \\
\text { management }\end{array}$ \\
\hline $\begin{array}{l}\text { Functional } \\
\text { organizational } \\
\text { structure enriched by } \\
\text { distinguishing key } \\
\text { cross-section } \\
\text { processes }\end{array}$ & $\begin{array}{l}\text { Owners functioning as directors and } \\
\text { Management Board representatives: high } \\
\text { quality, low costs, short delivery time, } \\
\text { environment safety and protection }\end{array}$ \\
\hline $\begin{array}{l}\text { Motivating } \\
\text { employees }\end{array}$ & $\begin{array}{l}\text { Extended, multifactor, including a significant } \\
\text { number of additional benefits (medical care, } \\
\text { leisure and recreation, education, life } \\
\text { insurance), the method for motivation staff } \\
\text { covering both joint and separate elements } \\
\text { depending on organizational structure } \\
\text { (marketing, construction and design office) }\end{array}$ \\
\hline Communication & $\begin{array}{c}\text { open to a great extent: consultancy, support in } \\
\text { education process, staff initiatives, } \\
\text { encouragement for presenting ideas, the } \\
\text { introduction of knowledge transfer } \\
\text { programme }\end{array}$ \\
\hline Career & $\begin{array}{c}\text { Internal recruitment is dominant, gradual } \\
\text { promotions, following consecutive } \\
\text { management stages }\end{array}$ \\
\hline Integrating activities & $\begin{array}{l}\text { Golden, silver and bronze badges awarded to } \\
\text { personnel for the number of years worked in } \\
\text { the company and input in its development, } \\
\text { carnival parties and family picnics for all } \\
\text { employees and their families, common trips } \\
\text { organized by particular teams, kaizen show - } \\
\text { monthly meetings of all manufacturing } \\
\text { department workers during which diplomas } \\
\text { and rewards are awarded for participation and } \\
\text { distinctive results in the suggestions } \\
\text { presenting programme. }\end{array}$ \\
\hline
\end{tabular}

Source: own study

However, it has to be emphasized that the preliminary sample of selected enterprises was too small to allow for presenting the final conclusions and generalizations. It has to be indicated that the results of initial research are mainly based on the first/initial observations made by the research team and their unrestrained inferences. However, certain common characteristics of enterprises are detectable which can be defined, with the great degree of caution, as the characteristics of Polish NMS (first observations):

- the desire to establish good relations between supervisors and co-workers,

- emotional relations between employees based on positive (sometimes negative) background and behaviour,

- the vital rank of personal relations,

- strong identification with an organization in terms of compassion for common fate,

- openness and even enthusiasm towards the new concepts,

- the desire do adapt various organizational and managerial solutions, however, experiencing difficulties related to their adjustment,

- formal approach to procedures, processes and terminology in the course of performing every day, routine management duties,

- flexibility in referring to the defined and written down agreement parameters,

- difficulties in maintaining the unchanging standards of activities and behaviours,

- searching for opportunities to speed up obtaining the final results,

- difficulties in defining individual responsibility.

\section{Conclusions}

The absence of theoretical research, which could refer to the identified characteristics of Polish national management style in an enterprise, is evident. This category, as the research direction, practically does not occur at the background of management science in Poland. The practice of fundamental, structural transformations, which has been going on in Poland and other countries introducing free market rules, has taken the long enough period to open the need for research covering the reasons and results of significant differences between management styles in these countries, as well as forecasting future processes, e.g. management convergence. The attempt to capture the influence of local factors on management processes, its confirmation or negation, defining the possible power, scope, importance and direction of such impact can be recognized as an important cognitive task.

\section{REFERENCES}

[1] Bjerke B., Business Leadership and Culture: National Management Styles in the Global Economy, Edward Elgar Publishing, Cheltenham, England, 1999.

[2] Gesteland R., Cross-Cultural Business behaviour: Marketing, Negotiating, Sourcing and Managing Across Cultures, Copenhagen Business School Press, Copenhagen, 2002..

[3] Hofstede G. Hofstede G.J., Minkov M, Cultures and Organizations. Software of the Mind, Mc Graw-Hill Companies, New York, 2010. 
[4] The Future of HR Profession. Eight leading Consulting Firms Share Their Visions for the Future of Human Resources. Society for Human Resources Management, Alexandria-Virginia, 2002.

[5] Trompenaars F., Hampden-Turner Ch., Seven Cultures of capitalism: Value Systems for Creating Wealth in the United States, Japan, Germany, France, Britain, Sweden and the Netherlands, Publishing by Doubleday, New York, 1993.

[6] Trompenaars F., Hampden-Turner Ch., Managing People Across Cultures, Capstone Publishing Ltd., London, 2004. 